引用格式:袁秀, 孙燕燕, 王计平, 等. 基于水鸟栖息地恢复的黄河三角洲水资源综合利用策略[J]. 资源科学, 2020, 42(1): 104114. [Yuan X, Sun Y Y, Wang J P, et al. Comprehensive utilization of water resources in the Yellow River Delta for waterfowl habitat restoration[J]. Resources Science, 2020, 42(1): 104-114.] DOI: 10.18402/resci.2020.01.11

\title{
基于水鸟栖息地恢复的黄河三角洲水资源 综合利用策略
}

\author{
袁 秀 $^{1}$, 孙燕燕 $^{2}$, 王计平 $^{3}$, 于莉莉 ${ }^{2}$
}

（1.中国科学院科技战略咨询研究院，北京 $100190 ; 2$. 东营市自然资源局, 东营 257091 ;

3. 中国林业科学研究院国家林业和草原局盐碱地研究中心, 北京 100091)

\begin{abstract}
摘 要: 黄河三角洲是国际重要水鸟停歇地,由于受自然因素和人类活动的影响,该地区水鸟栖息地面积不断 减少, 生物多样性不断降低。通过引用淡水对栖息地进行恢复, 能大大提高水鸟的生境质量, 增加水鸟的多样性。 然而该地区淡水资源短缺, 农业、工业和生活用水量大, 生态用水量严重不足, 如何因地制宜地利用淡水、海水和废 水资源, 发挥湿地保护生物多样性及净化环境的功能成为水鸟栖息地恢复的关键问题。本文总结了黄河三角洲的 水鸟多样性及其生境需求, 归纳了水资源的应用现状。在淡水资源短缺情况下, 使用淡水、海水和废水 3 种不同水 源补给湿地时,水鸟及其栖息地的特征和面临的挑战。结合水鸟迁徙、黄河来水的时间特征、水鸟栖息地斑块尺度 和区域尺度需求特征、不同水源的用水现状、恢复效果及空间分布特征等要素, 提出了综合利用海水、淡水和废水 对区域和斑块尺度的生境类型进行配置的生态补水恢复模式,建议斑块尺度重点考虑水深及水面植被比例，区域 尺度重点考虑水资源分布及自然和人工不同类型湿地的空间优化配置, 最后从多样性维持以及不同水资源综合有 效利用方面提出了未来研究展望。本文结果旨在为黄河三角洲湿地恢复和水鸟生物多样性提高提供科学依据。
\end{abstract}

关键词: 水鸟;栖息地;淡水;废水;海水;海岸带湿地; 生物多样性;黄河三角洲

DOI :10.18402/resci.2020.01.11

\section{1 引言}

黄河三角洲泛指黄河在人海口多年来淤积、延 伸、摆动、改道和沉淀而形成的一个扇形地带, 是世 界上形成年代最晚的大河三角洲湿地,也是中国乃 至世界暖温带最完整、最典型、最年轻的滨海河口 湿地生态系统 ${ }^{[1]}$ 。习近平总书记在黄河流域生态保 护和高质量发展座谈会中指出 “黄河三角洲要做好 保护工作, 促进河流生态系统健康, 提高生物多样 性”; 明确了黄河三角洲的发展方向, 做好黄河三角 洲生态保护工作, 对促进黄河流域生态健康具有特 殊意义。近年来, 因黄河三角洲淡水资源来源单 一, 导致湿地内部生态用水不足的问题愈发严重, 需秉承“重在保护, 要在治理” 的思想, 采取有效治
理措施, 以维持黄河三角洲湿地整体的生态功能。

黄河三角洲在全球水鸟保护中起着重要作 用。现代黄河三角洲是典型的滨海河口湿地, 具有 原生性、脆弱性、稀有性以及国际重要性等特征, 区 域内浅海滩涂、沼泽等湿地类型孕育了丰富的湿地 植被和水生生物资源, 是鸟类重要的庇护场所, 为 水鸟的繁衍生息、迁徙越冬提供了优良的栖息环 境, 是东亚一澳大利西亚、东北亚内陆和环西太平 洋鸟类迁徙路线上重要的停歇地和繁殖地。凭借 其拥有国际重要水鸟的数量, 在东亚一澳大利西亚 鸟类迁徙路线的各中途停留地点中, 黄河三角洲的 重要性排名第一 ${ }^{[2]}$; 有 42 种水鸟的 $1 \%$ 以上个体都会 栖息在黄河三角洲地区,该数量在中国列入《拉姆

收稿日期: 2019-12-17,修订日期: 2019-12-31

基金项目: 国家重点研发计划项目(2017YFC0505802-3)。

作者简介: 袁秀, 女, 重庆渝北区人, 助理研究员, 博士, 研究方向为资源环境可持续发展。E-mail: yuanxiu@casisd.cn 通讯作者: 孙燕燕,女, 山东东营市人, 高级工程师,博士, 研究方向为动物生态学。E-mail: sunyanyan8866@163.com 
萨尔公约》名录的国际重要湿地中居第一位 ${ }^{[3]}$ 。在 该区域分布有国家 I 级重点保护鸟类有 12 种,包括 东方白鹳(Ciconia boyciana)、丹顶鹤(Grus japonensis)、白鹤(Grus leucogeranus)、黑鹳(Ciconia nigra)、 白头鹤 (Grus monacha) 和遗鸥 (Larus relictus) 等水 鸟, 分布有国家 II 级重点保护的鸟类 51 种, 包括黑 脸琵鹭(Platalea minor)、白琵鹭(Platalea leucorodia)、灰鹤(Grus grus)、小杓鷸(Numenius minutus)、小 天鹅 (Cygnus columbianus)、大天鹅(Cygnus cygnus)、 疮鼻天鹅 (Cygnus olor)、卷羽鹈胡 (Pelecanus crispus)、白枕鹤(Grus vipio)和白额雁(Anser albifrons) 等水鸟。鸟类中还有 52 种被列入《濒危野生动植物 种国际贸易公约》, 有 152 种被列人《中华人民共和 国政府与日本政府保护候鸟及其栖息环境的协 定》,有 51 种被列人《中华人民共和国政府和澳大利 亚政府保护候鸟及其栖息环境的协定 $\rangle^{[4]}$ 。每年途 经黄河三角洲保护区的衍璚类水鸟达 110 余万只, 其中超过迁徙路线上同一种鸟类总量 $1 \%$ 的就有 17 种之多 ${ }^{[5]}$ 。但由于人类活动影响, 1999-2015 年, 经 过黄河三角洲的鸭敄类水鸟从 187296 只减少至 74412 只 ${ }^{[5]}$ 。通过明确保护水鸟多样性的管理目标, 有利于提高人们的资源利用意识和生态系统保护 意识 ${ }^{[6]}$,有利于黄河三角洲地区的有效管理。

水鸟群落是湿地生态系统的重要组成部分, 一 般被认为是生态系统中的顶级消费者 ${ }^{[7,8]}$, 食物网中 顶级消费者通过下行效应和营养级联效应影响自 养生物的组成与丰富度, 并促进生态系统多样性格 局转化和多稳态的产生, 从而为人类提供文化、调 节、支持等生态系统服务。例如水鸟通过捕食有害 生物减少鱼类死亡率、通过取食过程中扩散植物种 子促进植物在新的或恢复的湿地定居, 从而利于生 物多样性提高和维持 ${ }^{[9]}$; 研究证明滨鸟通过下行效 应直接影响着潮间带生态系统的稳定性 ${ }^{[10]}$ 。基于鸟 类在食物链和生态系统中的重要性及敏感性, 常将 水鸟作为湿地环境的指示物种, 开展面向水鸟群落 栖息地保护和恢复的研究,对维持黄河三角洲湿地 健康和生物多样性保护具有重要意义。

湿地水文条件是湿地类型和湿地功能最重要 的决定因子,不同水文条件赋予湿地生态系统不同 的物理和化学属性, 湿地水文的改变是决定湿地恢 复成功与否的关键因素 ${ }^{[1]}$ 。面向水鸟的湿地恢复措
施主要通过影响生境因子来影响湿地鸟类群落的 组成特征 ${ }^{[12]}$,通过为不同水鸟提供受食和歇息的环 境, 进而驱动湿地生态系统服务功能的改变; 常利 用补水措施影响水鸟生境的水深, 从而直接和间接 影响湿地内水鸟的食物类型、食物可获得性、环境 盐分浓度、植被类型、地形和水位波动等因子 ${ }^{[13]}$ 。由 此得出本文研究的依据:不同水源会产生不同的生 境类型,不同生境类型优势水鸟种群不同。

综上所述,本文的具体研究方法和思路为 : (1) 通过对文献资料综合分析, 确定黄河三角洲地区水 鸟现状、特征,及其不同类群对湿地的需求,依次明 确恢复目标湿地类型。2通过对遥感影像解译, 了 解湿地的现状及变化趋势, 据此可以明确水鸟栖息 地现状及潜在可恢复地区。(3)通过分析淡水、废水 和海水资源现状,包括水量、时空分布特征, 明确不 同水源可利用现状。(4)对利用淡水、废水和海水补 给湿地后,水鸟在不同湿地类型的分布状态及潜在 风险进行综述,为实施面向水鸟栖息地恢复的不同 水源利用策略提供基础。(5)最后综合黄河三角洲 的水鸟类型及其时间特征、不同水鸟对相应湿地的 利用情况、湿地空间分布现状、水资源时空现状及 不同水源恢复效果, 结合景观生态学理论, 提出相 应的基于水鸟栖息地保护与恢复多水源利用策 略。本文结果将为黄河三角洲地区有效利用水资 源恢复湿地, 以此保护和提高以水鸟为代表的生物 多样性提高科学依据。

\section{2 黄河三角洲水鸟多样性及生境需求}

\section{1 河海交汇作用下的黄河三角洲生物多样性}

黄河三角洲受到陆-海-河三者交互作用,陆海 物质交汇、淡咸水交融、径流和潮流相互作用、动力 过程复杂,形成了类型多样的陆上地貌、潮滩地貌 和潮下带地貌,包含了河流湿地、河滩湿地、河口湿 地、芦苇沼泽、潮间带滩涂湿地、潮上带盐碱化湿地 和柽柳灌丛沼泽等湿地类型。黄河三角洲孕育了 丰富的生物多样性,包括大型底栖动物 195 种, 维管 植物 382 种, 野生鸟类 368 种, 超过 200 种候鸟在此 栖息、停歇和越冬,鸟类种群数量超过 600 万只 ${ }^{\left[{ }^{6}\right.}$ 。 潮上带各类湿地类型中共有动植物 1490 种,包括维 管束植物 298 种、淡水浮游植物 291 种、陆生动物 901 种; 潮间带滩涂湿地中有海洋性水生动物 193 种; 潮下带浅海湿地中共有动植物 537 种,包括浮游 
植物 116 种、浮游动物 79 种、底栖动物 222 种、鱼类 112 种、其他动物 8 种 ${ }^{[14]}$ 。

\section{2 黄河三角洲水鸟及群落特征}

近年来, 黄河三角洲地区观察到的鸟类已达 368 种, 其中水鸟 80 种 ${ }^{[15]}$, 从居留型来看, 冬候鸟和 旅鸟最多 ${ }^{[16]}$ 。秋季鸟类种群数量最多, 其次是春季 和冬季。春季水鸟北上过境在 3-5 月, 高峰期在 4 月,秋季水鸟南下过境在 9-10月。该地区优势鸟 类主要为雁鸭类和行鸽类; 过境旅鸟以鸭敄类为 主, 春、秋季在该区短暂停歇; 越冬候鸟于 9 月下旬 至次年 3 月中旬停留在黄河三角洲, 以鹤类、鸥类和 雁鸭类等类群为主 ${ }^{[12]}$ 。

鸟类群落多样性与其赖以生存的栖息地密切 相关, 根据相近的生态习性和水鸟对栖息地的选 择 ${ }^{[17]}$, 常将水鸟分成 9 个相对稳定的生态类群: 鸬鹚 类、雁鸭类、秧鸡类、鸭䂆鸟类、鸥类、鹭类、鹤类和鹳 类 ${ }^{[15,18]}$ 。

\section{3 黄河三角洲水鸟及其生境}

水鸟组成 ${ }^{[19]}$ 与栖息地关系 ${ }^{[18,20]}$ 的研究表明, 在黄 河三角洲, 水鸟的生境偏好性相对稳定。水鸟体型 特征及食物偏好决定了不同栖息地分布不同类群： 水鸟的腿长、㖨长、颈长等特征对其生境选择有很 大影响; 食物偏好, 如鹤类喜好以种子为食, 鸭类大 多为杂食性, 小型鸭䂆鸟类多取食无脊椎动物, 鸹鹚 多以鱼类为生,决定着水鸟对栖息地类型的选择。

水鸟群落与湿地生境关系包括斑块尺度和区
域尺度 ${ }^{[12,21]}$, 区域尺度湿地面积、结构等因素影响水

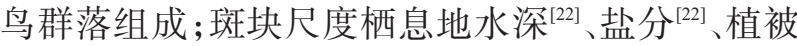
类型、植被盖度、植被高度等环境特征以及提供相 关食物的时间、多度、质量与适口性决定了不同湿 地类型上优势水鸟类型 ${ }^{[22]}$ 。

栖息地的水深是影响水鸟组合的最主要变 量 ${ }^{[22]}$ 。水鸟对栖息地水深的需求存在差异性, 小型 滨䂆鸟类在不到 $5 \mathrm{~cm}$ 深的水中受食; 大型行鵤可在水 深达 $15 \mathrm{~cm}$ 的水中受食; 大型涉禽 (如苍鹭、白鷺和 噮类) 和游禽 (如绿头鸭) 在水中受食深度达 $30 \mathrm{~cm}$; 潜水鸟类 (如鸬鹚和辟䝞) 需要最低水深大于 25 $\mathrm{cm}$, 可在几米深的水中活动 ${ }^{[13]}$ 。

从植被类型来看, 水鸟在黄三角地区主要栖息 于滩涂和芦苇沼泽;游禽主要栖息于芦苇沼泽、滩 涂; 涉禽主要栖息于滩涂, 芦苇柽柳沼泽中游禽和 涉禽都有分布; 芦苇、碱蓬柽柳沼泽中游禽明显多 于涉禽, 滩涂类型中涉禽占优势; 彻䂆鸟类主要在滩 涂活动 ${ }^{[23]}$ 。

在黄河三角洲,可以大致将水鸟栖息地分为浅 海滩涂、河流、芦苇沼泽等 7 个类型 ${ }^{[5]}$, 每种生境类型 分布的主要水鸟类群有所不同(表 1 )。

人工湿地和自然湿地内水鸟组成有一定差 别。 $\mathrm{Li}$ 等 ${ }^{[15]}$ 对比了黄河三角洲地区水产养殖场、稻 田、灌溉渠、水库和盐田等 5 类人工湿地与自然湿地 对冬季水鸟的影响, 结果表明: 人工湿地具有给水 鸟提供临时性栖息地的功能 ${ }^{[2]}$ 。虽然废水灌溉对环

\section{表 1 黄河三角洲水鸟及其生境}

Table 1 Main bird species and their habitats in the Yellow River Delta

\begin{tabular}{|c|c|c|c|}
\hline 生境类型 & 类型界定 & 生境特征 & 主要水岛 \\
\hline 浅海滩涂 & 潮汐定期涨落和淹没区域 & 大量底栖生物, 是众多水鸟的食物 & 行类、鹬类、鹭类、鸥类、鸬鹚类、雁鸭类、鹤类 \\
\hline 河流 & $\begin{array}{l}\text { 黄河、小清河、广利河、支脉河、小岛 } \\
\text { 河等河流 }\end{array}$ & $\begin{array}{l}\text { 盛产鱼、虾等水生物, 水底有大量水 } \\
\text { 草,河滩周围有大量湿生植物, 是鸟类 } \\
\text { 理想环境 }\end{array}$ & 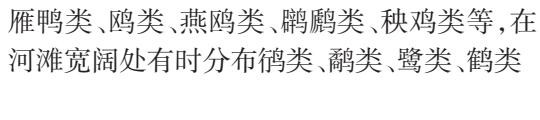 \\
\hline 芦苇沼泽 & 以芦苇为主要植物群落的沼泽湿地 & 不同水深梯度,水鸟集中区域 & $\begin{array}{l}\text { 鹤类、鹳类、雁鸭类、鸥类、燕鸥类、辟仿鸟类、秧 } \\
\text { 鸡类、鸬鹚类、胻类、㛚类、鹭类 }\end{array}$ \\
\hline $\begin{array}{l}\text { 水库及周 } \\
\text { 围沉沙池 }\end{array}$ & 存储淡水的水库, 及周围沉沙池 & $\begin{array}{l}\text { 水库面积广阔,鱼、虾丰富;部分沉沙 } \\
\text { 池有水草、芦苇沼泽等生境 }\end{array}$ & 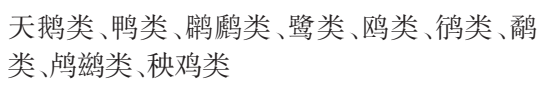 \\
\hline 人工池塘 & 以水产养殖、村庄饮水为目的的池塘 & $\begin{array}{l}\text { 呈斑块状分布,面积或大或小, 水边常 } \\
\text { 生长有芦苇、香蒲等湿生植物, 水中生 } \\
\text { 长有狐尾藻、眼子菜等沉水水生植物 }\end{array}$ & 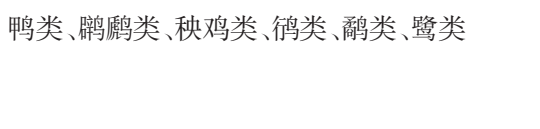 \\
\hline $\begin{array}{l}\text { 盐池及海 } \\
\text { 产养殖池 }\end{array}$ & 近海开发的盐池及海产养殖池 & 大面积分布 & 行类、㛚类、鹭类、鸥类、鹤类 \\
\hline 农田 & 冬小麦、大豆等农田,以及水稻田 & 丰富的食物 & 行类、鸽类、鹭类 \\
\hline
\end{tabular}

注:编引自《黄河三角洲鸟类》 ${ }^{[23]}$ 
境土壤存在潜在风险,但污水生境包括污水处理厂 和废水处理湿地也能够为水鸟提供活动空间; 同时 水鸟对人工湿地的生境利用不仅受到栖息地本身 特征的影响,还受到周围景观性质的影响 ${ }^{[24]}$ 。

\section{4 黄河三角洲水鸟栖息地面临多重威胁}

黄河三角洲地区自然湿地面积缩小, 近海滩涂 湿地退蚀, 鸟类栖息地缩减。通过遥感影像解译和 调查发现,2019年东营市地区盐田面积 $40128 \mathrm{hm}^{2}$ 、 内陆滩涂 $27705 \mathrm{hm}^{2}$ 、沿海滩涂 $94037 \mathrm{hm}^{2}$ 、水田 $22633 \mathrm{hm}^{2}$ 、河流水面 $15332 \mathrm{hm}^{2}$ 、水库水面 18037 $\mathrm{hm}^{2}$ 、坑塘水面 $95758 \mathrm{hm}^{2}$ 、浅海海域 $156814 \mathrm{hm}^{2}$, 合 计湿地 $470444 \mathrm{hm}^{2}$ (图 1)。2013-2019年东营市湿 地变化 (图 2)显示出: (1)自然湿地缩减,人工化趋势 加大; 自然湿地从 2013 年的 $339963 \mathrm{hm}^{2}$ 减少到 2019 年的 $137319 \mathrm{hm}^{2}$; 人工湿地从 2013 年的 $116810 \mathrm{hm}^{2}$ 增加到 2019年的 $218245 \mathrm{hm}^{2}$ 。(2)沼泽湿地退化面 积 $41854 \mathrm{hm}^{2}$, 退化为盐碱地和草地; 沿海滩涂面积 减少 $37455 \mathrm{hm}^{2}$, 转换为内陆滩涂和坑塘水面、盐田、 沟渠等,部分退化为盐碱地和草地。

黄河三角洲水鸟栖息地同时面临沿海开垦 ${ }^{[2]}$

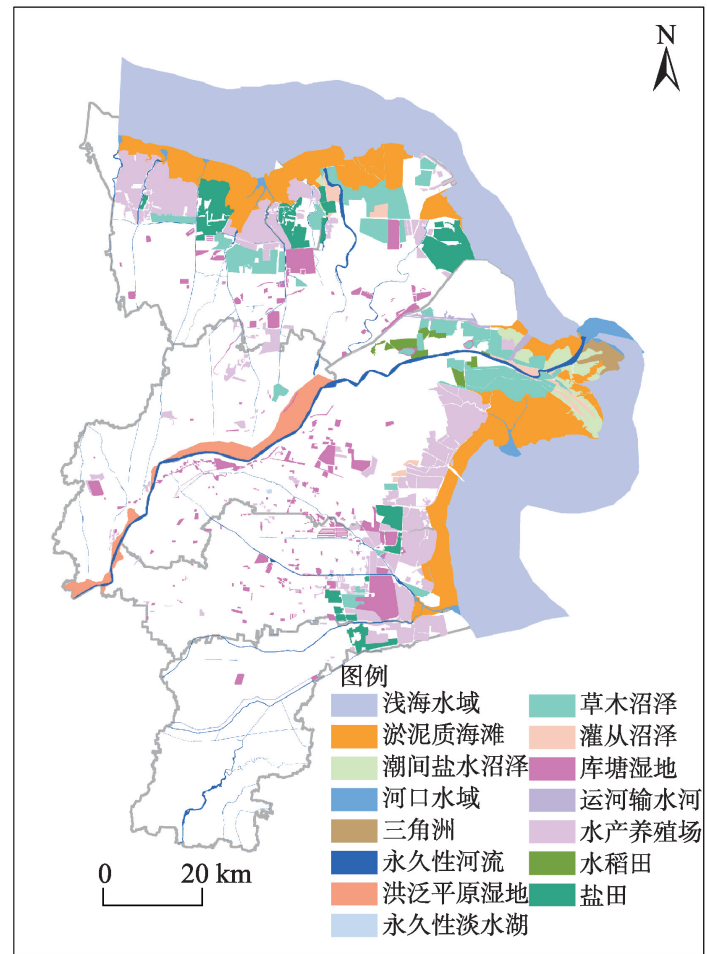

图 12019 年东营市湿地格局

Figure 1 Pattern of wetlands in Dongying City, 2019
滩涂养殖、围海筑堤、海港建设、沿海大通道建设、 外来物种人侵、城市化、农业发展、工业、石油开发、 污染 ${ }^{[5]}$ 及海水养殖和盐业扩张带来的湿地丧失和质 量退化的问题。黄河来水、来沙影响黄河口湿地, 老河口湿地面积总体呈减小趋势,新河口呈现出先 增后减的趋势 ${ }^{[25]}$ 。在此背景下,水鸟保护的关键问 题是如何通过改善湿地来提供合适的栖息地 ${ }^{[13]}$ 。

\section{3 黄河三角洲水资源现状与挑战}

中国快速的社会经济发展给黄河流域用水带 来了更大的压力, 农业、工业和人口的增长将进一 步增加对水的需求,而环境污染已经成为黄河三角 洲的主要环境威胁之一 ${ }^{[1]}$ 。目前, 只有黄河水是该 地区可开发利用的淡水资源。区内还有十余条河 流主要用于排碱、排涝和排污,如沾利河、草桥沟、 挑河、神仙沟支脉河、永丰河、张镇河、小岛河等(图 3 ); 黄河以北河流属于海河流域, 流人渤海; 黄河以 南河流属于淮河流域, 流人莱州湾 ${ }^{[26]}$ 。

\section{1 淡水资源短缺}

黄河三角洲水资源补给主要有大气降水与过 境河流补给 2 种方式, 区域内淡水资源总量多年平

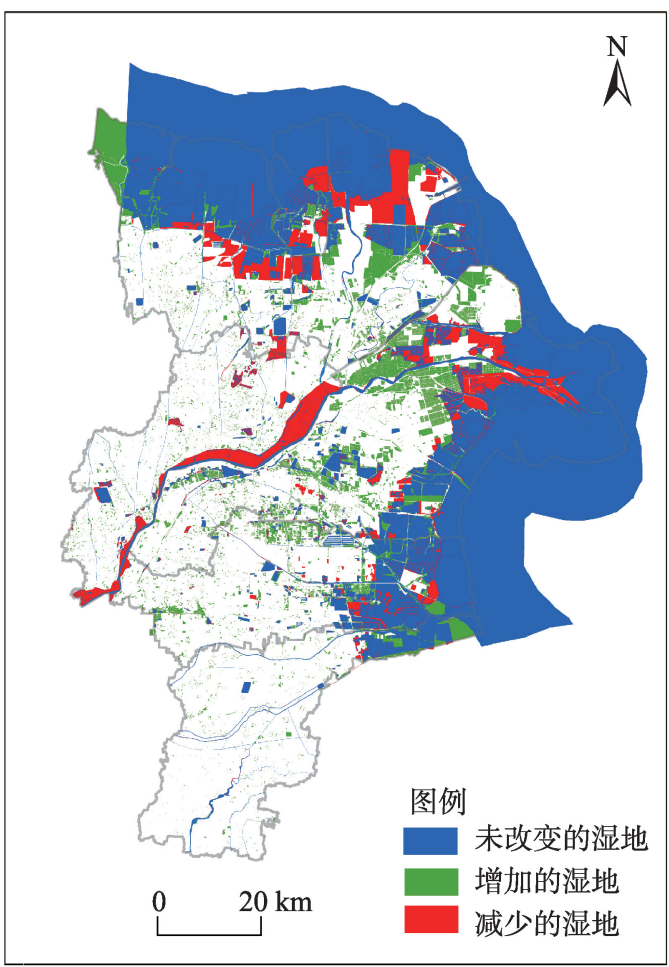

图 $22013-2019$ 年东营市湿地变化

Figure 2 Wetland changes in Dongying City, 2013-2019 
均约为 29 亿 $\mathrm{m}^{3}$, 人均占有 $296 \mathrm{~m}^{3}$, 仅为全国的 $1 / 6$, 属严重缺水地区。(1)就降水条件而言, 作为黄河三 角洲中心城市的东营地区, 多年平均降水量为 537 $\mathrm{mm}, 75 \%$ 集中在汛期 6-9 月,其他季节干旱少雨。 多年平均蒸发量为 $1885 \mathrm{~mm}$, 蒸发量是降水量的 3.5 倍。多年地表水资源量 4.3 亿 $\mathrm{m}^{3}$, 地下水资源量 2.6 亿 $\mathrm{m}^{3}$, 扣除地表水、地下水重复计算量,多年平均水 资源总量为 6.2 亿 $\mathrm{m}^{3}$, 严重缺水 ${ }^{\circledR}$ 。(2)就过境河流补 给而言,东营市过境水资源补给主要有黄河、小清 河、支脉河和淄河。小清河、支脉河多年平均人境 水量分别为 5.21 亿和 2.46 亿 $\mathrm{m}^{3}$ 。黄河水是唯一可 大规模开发利用的淡水水源,多年平均流量为 314.7 亿 $\mathrm{m}^{3}$,东营分配的引黄指标为年 22.7 亿 $\mathrm{m}^{3}$; 黄河来 水来沙量年际和年内分配不均匀,年内来水主要集 中于 8、9 月,3-6月期间黄河水流流量较小。黄河 人海流量减少, 会直接减少黄河三角洲的水资源补 给, 导致该地区湿地生态系统退化, 从而影响栖息 在此的水鸟及其他生物的生存和繁殖。

\section{2 生态用水缺乏保障}

2012-2015 年东营市年均供水量为 9.33 亿 $\mathrm{m}^{3}$, 其中主要来源是调水引黄, 水量为 6.68 亿 $\mathrm{m}^{3}$, 当地 地表水为 1.76 亿 $\mathrm{m}^{3}$; 地下水为 0.79 亿 $\mathrm{m}^{3}$; 其他水源, 如污水处理回用和集雨工程供水,供水量为 0.10 亿

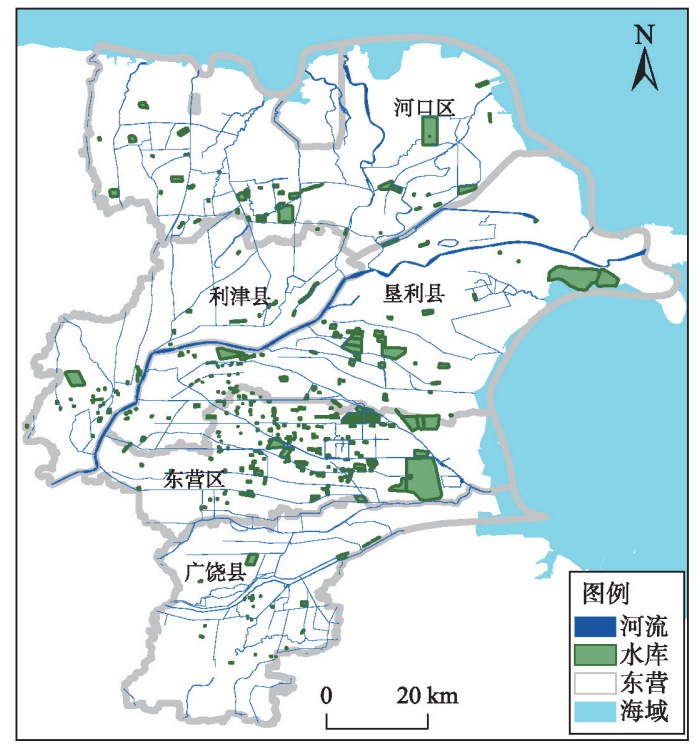

图 3 黄河三角洲不同水源类型及其分布

Figure 3 Distribution of water sources in the Yellow River Delta $\mathrm{m}^{3}$ (图 4)。2012-2015 年平均总用水为 8.97 亿 $\mathrm{m}^{3}$, 其中占比最多的是灌溉用水,为 5.72 亿 $\mathrm{m}^{3}$, 占总用 水量的 $64 \%$; 生态用水占比最少, 为 0.45 亿 $\mathrm{m}^{3}$, 占总 用水量的 $5 \%$; 工业用水 1.69 亿 $\mathrm{m}^{3}$; 居民生活用水 1.11 亿 $\mathrm{m}^{3}$ (图 5)。东营市年需生态补水量大约为 1.5 亿 $\mathrm{m}^{3}$ (表 2$)$, 远大于 $2012-2015$ 年平均生态用水 量 0.45 亿 $\mathrm{m}^{3}$,生态用水缺乏保障。

\section{3 水污染日益严重}

东营市黄河干流及耿井水库、南郊水库、辛安 水库、孤河水库、孤东水库、胜利水库、永镇水库、城 南水库 8 个饮用水水源地水质能达到 III 类水标准。 省控及以上河流中广利河、太平河、小清河、阳河、 织女河、支脉河等水质为 $\mathrm{V}$ 类水，中度污染; 挑河、 溢洪河、神仙沟等水质为劣 $V$ 类, 重度污染; 市控重
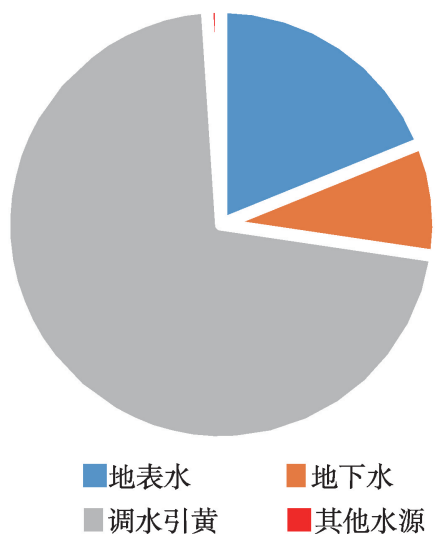

图 4 东营供水来源

Figure 4 Water sources in Dongying City

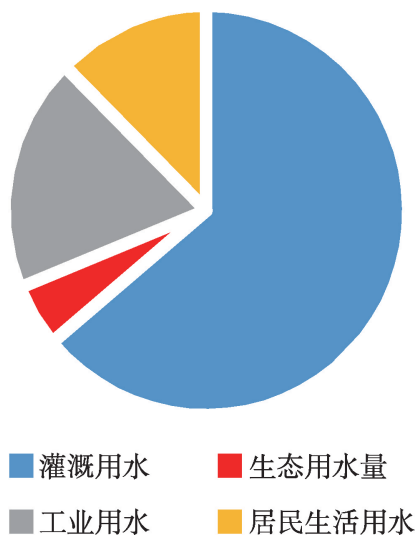

图 5 东营用水渠道

Figure 5 Water uses in Dongying City

(1) 东营市水资源数据来源于东营市政府《东营市全面建设生态城市 “五水统筹”工作方案 (2018)》。 
表 2 东营市主要修复地区生态补水量

Table 2 Water required for key wetlands in Dongying City

\begin{tabular}{lc}
\hline \multicolumn{1}{c}{ 湿地 } & 生态补水量 $\left(\right.$ 万 $\mathrm{m}^{3} /$ 年 $)$ \\
\hline 黄河三角洲国家级自然保护区 & 6000 \\
东营龙栖湖省级湿地公园 & 100 \\
河口鸣翠湖省级湿地公园 & 20 \\
山东旺利天宁湖国家湿地公园 & 1500 \\
等利米荷湾省级湿地公园 & 100 \\
垦利兴隆省级湿地公园 & 100 \\
广饶孙武湖省级湿地公园 & 3000 \\
广饶县支脉河湿地公园 & 2000 \\
沾利河湿地公园 & 49 \\
太平河湿地公园 & 300 \\
东津湿地公园生态 & 602 \\
共计 & 14671 \\
\hline
\end{tabular}

点河流预备河、广蒲河、东营河、永丰河、草桥沟等 均为劣 $\mathrm{V}$ 类水, 为重度污染。从整体来看, 东营市 湿地水质情况较差, 除少数湿地水质优良外, 均受 到不同程度的污染,超标项目主要为重金属、石油 类、化学需氧量 $(C O D)$ 、氨氮和总磷等。污染源主 要是城镇生活、外来人境污染 (小清河主要污染源 来自上游济南、淄博、滨州等市企业排放污废水; 支 脉河污染源主要来自上游博兴县和高清县的企业 污废水)、农业面源污染(化肥、农药)、工业污废水 (造纸、石油、COD排放量)、油区落地原油等。同时 黄河口近海水域水质也在不断下降, 造成近海与海 岸湿地生境遭到破坏,生物多样性衰减 ${ }^{[26]}$ 。

\section{4 综合利用多水源恢复重建水鸟栖 息地}

随着自然和人类活动影响, 黄河三角洲地区水鸟 栖息地数量和质量下降,基于该地区淡水资源短缺、 水环境污染加剧以及生态用水缺乏保障的现状,可综 合利用淡水、废水和海水对水鸟栖息地进行恢复。对 淡水、废水和海水补给后,形成的不同生境类型及分 布的相应水鸟类型进行总结(图6), 当确定需要提 升水鸟类型及数量时, 即可判断所需要生境类型, 根据区域生态系统中水源分布,制定合理的引水方 案和措施,实现生境恢复、资源合理利用、环境净化等 多方面功能, 提升湿地系统的整体生态功能。以下 将分别从不同水源利用措施、对水鸟的影响、恢复 措施潜在风险等几个方面进行阐述。

\section{1 利用淡水恢复重建水鸟栖息地}

4.1.1 淡水水源特征与恢复措施

黄河三角洲地区淡水水源为黄河与相关水库 内存水。近年来,黄河三角洲地区年均引淡水约 3000 万 4000 万 $\mathrm{m}^{3}$ 。黄河为多泥沙河流, 径流量随 季节性变化大。为保证黄河的功能性流量和堤防 防洪安全,防止渠道淤积,一般在利津水文站流量 小于 $100 \mathrm{~m} / \mathrm{s}$ 或超过 $5000 \mathrm{~m} / \mathrm{s}$ 时不引水;来水含沙量 超过 $30 \mathrm{~kg} / \mathrm{m}^{3}$ 时不引水;一般流冰期不引水 ${ }^{[27]}$ 。

引用淡水对水鸟栖息地恢复的措施包括引灌 黄河水、沿海修筑围堤和增加湿地淡水存量等措

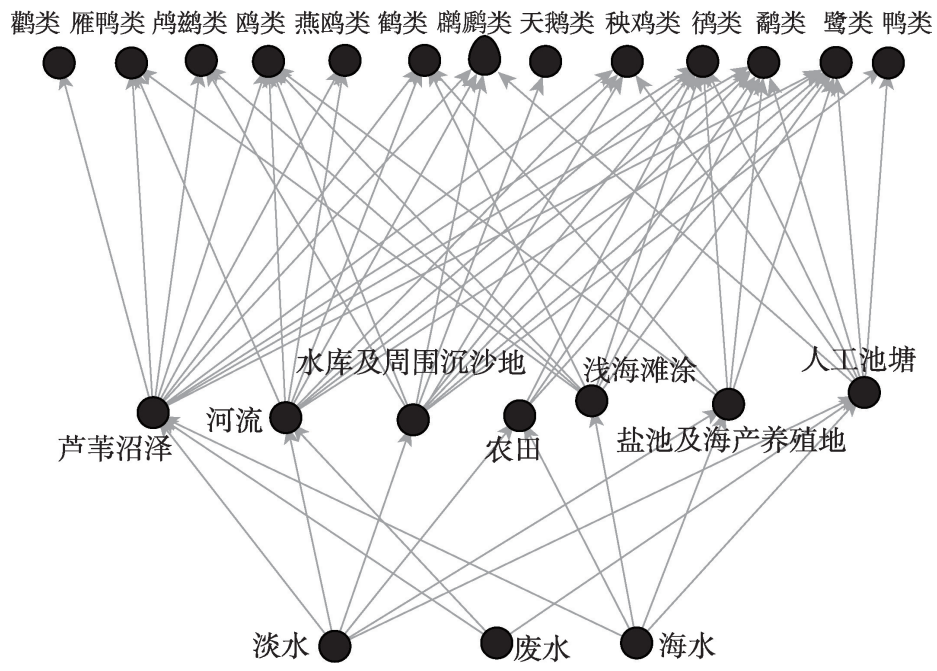

图 6 不同水源恢复下的水鸟栖息地

Figure 6 Bird habitats under different water source restoration scenarios 
施, 通过引人淡水, 水资源得到充分供给, 从而改变 了土壤的化学性质, 降低了地表水分蒸发引起的地 表积盐, 同时通过地表径流溶盐洗碱, 使恢复区内 土壤盐分逐年下降 ${ }^{[28]}$; 引用黄河水还能提供营养和 沉积物, 使植被盖度增加、植被类型改变等, 改变栖 息地环境。

\subsection{2 淡水恢复效果与面临的挑战}

自 2001 年开始,在黄河三角洲开始实施淡水补 水工程, 通过修筑围堤和引水渠, 在雨季蓄积雨水、 在黄河丰水期引蓄黄河水, 调控湿地水位和水面面 积, 恢复退化的淡水湿地生态系统。结果显示淡水 湿地恢复对水鸟多样性有明显提高, 恢复时间越 长, 湿地鸟类群落多度和丰富度越高, 尤其是提高 了微䂆鸟类、雁鸭类和鹳类的丰富度 ${ }^{[12]}$ 。2010 年在入 口实施的生态调水, 修复湿地 2.3 万 $\mathrm{hm}^{2}$, 以解决黄 河三角洲自然保护区北区湿地水盐失衡、生态系统 退化等问题 ${ }^{[11]}$ 。有研究表明 2010 年和 2011 年水禽 数量分别增加了 11180 只和 36798 只; 指示性物种丹 顶鹤、黑鹳、白鹤适宜生境面积增加明显, 单顶鹤分 别增加了 11 只和 19 只, 黑鹳分别增加了 14 只和 4 只, 东方白鹳分别增加了 18 只和 149 只, 2011 年东 方白鹳出现 152 只大群迁徙种群, 首次发现白鹤种 群 14 只 ${ }^{[30]}$ 。

淡水恢复水鸟栖息地也面临挑战,具体包括: (1)淡水湿地补水并不能使所有鸟类生境都得到改 善。例如,过多补给淡水对于黑嘴鸥栖息地质量有 不利一面 ${ }^{[3]}$ 。因此在海岸带地区, 通过补给淡水进 行湿地恢复需适度, 保持栖息地类型多样性。淡水 过多或过少都会对鱼类产卵、贝类生存、鸟类筑巢、 种子繁殖以及鱼类和野生动植物的其他季节性活动 产生不利影响。(2)引黄河水时间有限。黄河作为主 要淡水来源, 主要在 7-8 月水量适合引流, 而黄河 三角洲地区淡水湿地关键需水期为每年 3-5 月和 7-9月上旬。因此在旱季, 需要考虑库塘作为水源 对湿地进行补给, 保证湿地生态需水量。(3)淡水资 源有限。保证自然保护区淡水湿地稳定发育的最 小生态需水量为 2.8 亿 $\mathrm{m}^{3}$, 在该水量下鸟类栖息地 功能才能基本发挥, 生物多样性才能得到逐步恢 复 ${ }^{[30]}$ 。

\section{2 利用废水恢复重建水鸟栖息地}

\subsection{1 废水水源特征与恢复措施}

黄河三角洲地区的河流有 15 条处于重度污染 状态, 3 条受到轻度污染, 污染有不断加剧的趋势。 区内的挑河、神仙沟、支脉河、广利河、溢洪河、小清 河、渤海湾 7 个主要水系的 11 条河流是主要的纳污 水系。在工业废水中,主要污染物包括 COD、石油 类、悬浮物和挥发酚等。生活污水中主要污染物是 $\mathrm{COD}$ 、总悬浮固体、含硫化合物和大肠杆菌等 ${ }^{2}$ 。

东营市污水、雨水、大量的灌溉尾水经河道直 接人海, 非常规水资源 (雨水、再生水、灌溉尾水等) 利用水平较低,合理开发利用当地非常规水资源是 缓解当地水资源供需矛盾的重要手段 ${ }^{[31]}$ 。将废水定 义为水通过非消费性用途后, 仍可以被收集、处理、 再利用的水资源,如工业用水、生活用水 ${ }^{[17]}$ 。废水湿 地包括污水处理池 (Waste Stabilization Ponds) 和废 水处理湿地 (Constructed Wetlands), 它们本身可以 为水鸟保护提供临时的栖息地 ${ }^{[32]}$ 。

4.2.2 废水恢复效果与面临的挑战

未经处理的河流污水为河口鸟类群落提供了 直接和间接的食物资源 ${ }^{[34]}$, 如海鸥可以在未经处理 的污水湿地中受食; 污水排放到河口海岸带湿地, 能增加底栖生物的多样性, 为水鸟提供食物 ${ }^{[3]}$ 。再 生水处理厂附近水鸟有增加趋势 ${ }^{[35]}$, 如墨尔本西南 部的西部污水处理厂(Western Treatment Plant) 地 区,维持了较高的水鸟多样性,被列为维多利亚州 的五大水鸟湿地之一 ${ }^{[32]}$ 。

必须指出,废水湿地作为水鸟栖息地存在一定 的生态风险。废水中通常含有大量重金属和其他 化学污染物,这些污染物可能对鸟类的健康构成重 大威胁 ${ }^{[18]}$ 。随着水鸟对污水处理池和其他废水处理 湿地的依赖性日益增加, 废水中污染物和疾病对水 鸟的影响可能增加, 由此可能引起水鸟疾病在人类 中传播。因此需要研究和积极管理, 以有效、安全 地实现废水处理和水鸟栖息地的双重目标,达到既 可控制病原菌又可控制废水中污染物的处理目标。

\section{3 利用海水恢复重建水鸟栖息地}

\subsection{1 海水水源特征与恢复措施}

按 GB3097-1997《海水水质标准》 II 类标准进行

(2) 水源污染数据来源于山东省环境保护科学研究设计院《东营市生态环境保护“十三五”规划技术报告 (2017)》。 
评价, 黄河三角洲海水主要污染物是 COD、铅、活动 磷酸盐和石油类。海水温度、盐度受大陆气候和黄 河径流的影响较大。冬季沿岸有 2 个月冰期, 海水 流冰范围为 $0 \sim 5$ 海里, 盐度在 $35 \%$ 左右; 春季海水温 度为 $12 \sim 20{ }^{\circ} \mathrm{C}$, 盐度多为 $22 \% 0 \sim 31 \%$; 夏季海水温度 为 $24 \sim 28{ }^{\circ} \mathrm{C}$, 盐度为 $21 \% 0 \sim 30 \%$ 。潮汐属不规则日 潮和不规则半日潮的不同潮型, 每日 2 次, 潮流为来 复流, 潮差一般为 $2 \mathrm{~m}$, 潮汐流速平均为 1.1 海里/小时。

海岸带水鸟具有一套形态、生理和行为机制, 能够在不同盐度环境中生活和受食 ${ }^{[35]}$, 为利用海水 对水鸟栖息地进行恢复提供了可能。海水灌溉通 常包括在淡水灌溉的基础上间或灌溉海水、用低浓 度海水喷灌、直接用海水浇灌或漫灌 3 种灌溉方 式。形成的湿地类型包括潮水引人和人工引用海 水形成的盐沼, 以及各种水产养殖活动, 例如贝类 或鱼类养殖场。

\subsection{2 海水恢复效果与面临的挑战}

适当的海水恢复措施, 可以显著改善鸟类生 境。如崇明东滩通过潮汐作用下引入海水修复湿 地, 在大潮期间辅助少量人工引导潮水, 营造潮沟 和光滩生境, 为水鸟提供了食物来源, 促进了水鸟 多样性提高, 滨鸟、潜水鸟类、溅水鸭类、鹭均对海 水恢复湿地表现出明显偏好 ${ }^{[36]}$ 。

科学海水养殖 (滩涂养殖、围海养殖) 既可提供 经济来源, 又能为水鸟提供栖息和受食场所。如广 东海丰湿地在粗放型海水养殖过程中, 会定期降低 养殖塘中的水位, 由此提供的开阔、人为干扰少且 不同水深的浅水区，吸引了包括雁鸭类、鹭类、微䂆岛 类等数以千计的水鸟前往栖息和受食 ${ }^{[37]}$ 。但同时不 科学的海水养殖会破坏近海生态环境, 养殖本身会 占用水鸟栖息地和受食地,会造成近海环境有机 物、营养盐、重金属和抗生素污染 ${ }^{[38]}$ 。因此建议在利 用海水来恢复水鸟栖息地过程中, 结合人工保护和 自然修复的理念, 加强滩涂等自然湿地保护及其生 态过程维持。此外, 用海水漫灌, 有可能引起土壤 严重盐渍化、海水恢复需要注意在持续监测下逐步 实施; 同时为有效引用海水需要对地区进行科学的 选择, 对潮水运行规律、海水中泥沙和生物对恢复 湿地的影响相关方面进行深入研究。

\section{5 结论、建议与研究展望}

\section{1 结论与建议}

由于水鸟有不同的栖息地使用偏好, 修复河口 受损生态系统和实施人工补水过程中,需要统筹考 虑保护对象的生境和景观多样性, 科学修复与谨慎 重建不同功能的湿地,协调好不同保护种群的栖息 生境需求。结合湿地需要,合理利用淡水、废水和 海水资源, 确定不同水鸟恢复目标, 即确定在哪恢 复、恢复成什么、用什么水恢复、采取什么措施等问 题。有效恢复退化湿地生态系统, 提高湿地质量和 湿地生物多样性,切实提升湿地保护成效,为鸟类 栖息和鱼类繁殖创造更优良的湿地生态环境, 以保 证黄河三角洲高质量发展, 具体建议如下:

(1) 用水保障上面, 提高淡水利用率。从用水 量上看,东营地区农业用水比例还较高,利用率低,应 在农业上提高用水利用率, 为生态用水提供保障。

(2)综合利用淡水、海水和废水,优化配置, 达 到最佳效果。基于淡水资源短缺,能利用黄河水的 时间大多 7-8 月; 基于水鸟对栖息地多样性的需 求,应重点发挥淡水和海水在水鸟栖息地保障上的 作用; 同时,应积极发挥湿地的生态功能,合理利用 工业、农业、生活用水废水处理,使污水得到二次利 用,用于恢复湿地。为此,建议开展基于水鸟栖息 地保护与恢复的多水源综合利用策略的研究,集合 不同水源水量、水质、空间分布等特征,发挥 3 种水 源优势, 对不同水源在黄河三角洲地区应用后的风 险进行防范。

（3）由于水深及其营造的湿地类型对水鸟类型 影响大, 斑块尺度可营造出不同地势, 通过水位调 控构建多样的微生境, 注意水面与植被面积的组合 比例, 实现景观多样性与生态系统功能同步提升。 同时可以利用生态浮床提高水鸟利用效率,改善水 鸟栖息环境。

(4) 同一种水鸟需要不同生境类型的组合,所 以,在景观尺度范围内需要考虑在一定区域范围内 不同生境类型组合的营造,如彻璚水鸟需要水域、 裸地、植被 3 种生境单元的同时出现。基于水资源 分布空间格局、水鸟对区域尺度格局的需求、土地 基底特征、不同水源的恢复效果,面向水鸟多样性 
区域尺度需求, 优化景观中斑块组成类型、数量及 生态连通性。可在沿海滩涂恢复近海湿地生物栖 息地,在河口地区构建东方白鹳、黑嘴鸥、丹顶鹤栖 息繁殖区,在黄河沿岸两侧库塘营造岛类栖息地。

(5) 黄河来水时间、黄河三角洲以水鸟迁徙旅 鸟为主这 2 个主要特征, 决定了黄河三角洲湿地的 季节性变化特征。在黄河水缺乏时,考虑从水库中 补水; 同时发挥废水湿地、海水湿地的替代性作用， 可以在不同季节营造不同生境类型特征的人工湿 地, 以适应不同水鸟的迁徙规律, 为水鸟顺利迁徙、 繁殖提供保障。

\section{2 研究展望}

管理者制定技术、经济和环境适宜的管理计 划, 需要了解沿海地区生态系统的复杂性, 建议对 以下 4 个方面继续研究:

(1) 滨海滩涂湿地功能稳态与生物多样性维持 机制研究。对不同水源湿地内的食物网进行分析, 以利于实现以水鸟多度和丰富度提升为代表的多 样性保护。

(2)对水鸟栖息地恢复优化技术研究。科学地 明确水鸟类型及多度提升目标, 以此确定需要恢复 湿地的类型及面积,结合水鸟恢复目标、水资源类 型及时空分布、现有土地利用状态,综合不同引水 方案,空间优化不同栖息地类型、分布及采用措施。

(3)不同水源利用过程中物理和生物组合影响 过程研究。不同水资源中物质类型各样,如淡水中 沙、海水中生物和盐分、废水中污染物质都会影响 不同水源的利用,利用过程中物理和生物过程复 杂, 对这些影响过程进行研究, 利于确定合适的水 资源开发利用措施。

(4) 湿地不同恢复措施长时间的恢复效果研 究。引水时间、引水量、水深以及维持时间对水鸟 栖息地环境及植被类型作用大,对不同水源在长时 间恢复效果及风险进行研究, 利于科学判断恢复效 果及存在风险。

\section{参考文献(Reference):}

[1] 陈怡平, 傅伯杰. 关于黄河流域生态文明建设的思考 [N/OL]. (2019- 12- 20) [2019- 12- 26]. http://www.cas.cn/zjs/201912/ t20191220_4728425.shtml. [Chen Y P, Fu B J. Think about Ecological Civilization Construction in the Yellow River Basin[N/OL]. (2019- 12- 20) [2019- 12- 26]. http://www.cas.cn/zjs/201912/ t20191220_4728425.shtml.]

[2] Li X W, Hou X Y, Song Y, et al. Assessing changes of habitat quality for shorebirds in stopover sites: A case study in Yellow River Delta, China[J]. Wetlands, 2019, 39(1): 67-77.

[3] Ma T T, Li X W, Bai J H, et al. Habitat modification in relation to coastal reclamation and its impacts on waterbirds along China's coast[J]. Global Ecology and Conservation, 2019, 17: 1-10.

[4] Bai Q Q, Chen J Z, Chen Z H, et al. Identification of coastal wetlands of international importance for waterbirds: A review of China Coastal Waterbird Surveys 2005-2013[J]. Avian Research, 2015 , (3): 153-168.

[5] 张晓龙, 李萍, 刘乐军, 等. 黄河三角洲湿地生物多样性及其保 护[J]. 海岸工程, 2009, 28(3): 33-39. [Zhang X L, Li P, Liu L J, et al. Biodiversity and its protection in the Yellow River Delta Wetland[J]. Coastal Engineering, 2009, 28(3): 33-39.]

[6] 崔保山, 李英华, 杨志峰. 基于管理目标的黄河三角洲湿地生态 需水量[J]. 生态学报, 2005, (3): 606-614. [Cui B S, Li Y H, Yang Z F. Management-oriented ecological water requirement for wetlands in the Yellow River Delta[J]. Acta Ecologica Sinica, 2005, 25(3): 606-614.]

[7] Steinmetz J, Kohler S L, Soluk D A. Birds are overlooked top predators in aquatic food webs[J]. Ecology, 2003, 84(5): 1324-1328.

[ 8 ] Leat E H K, Bourgeon S, Magnusdottir E, et al. Influence of wintering area on persistent organic pollutants in a breeding migratory seabird[J]. Marine Ecology Progress Series, 2013, 491:277-293.

[9] Green A J, Elmberg J. Ecosystem services provided by waterbirds [J]. Biological Reviews, 2014, 89(1): 105-122.

[10] Sinclair A R E, Mduma S, Brashares J S. Patterns of predation in a diverse predator- prey system[J]. Nature, 2003, 425(6955): 288290.

[11] Zhao Q Q, Bai J H, Huang L B, et al. A review of methodologies and success indicators for coastal wetland restoration[J]. Ecological Indicators, 201, 60: 442-452.

[12] 王明春. 黄河三角洲湿地恢复对湿地鸟类群落的效应研究[D]. 曲阜: 曲阜师范大学, 2008. [Wang M C. Effect of Wetland Restoration on Wetland Bird Community in the Yellow River delta[D]. Qufu: Qufu Normal University, 2008.]

[13] Ma Z J, Cai Y T, Li B, et al. Managing wetland habitats for waterbirds: An international perspective[J]. Wetlands, 2010, 30(1): 1527.

[14] 张绪良, 肖滋民, 徐宗军, 等. 黄河三角洲滨海湿地的生物多样 性特征及保护对策[J]. 湿地科学, 2011, 9(2): 125-131. [Zhang X L, Xiao Z M, Xu Z J, et al. Biodiversity characteristics and protection countermeasures of the coastal wetlands in the Yellow Del- 
ta[J]. Wetland Science, 2011, 9(2): 125-131.]

[15] Li D L, Chen S H, Lloyd H, et al. The importance of artificial habitats to migratory waterbirds within a natural/artificial wetland mosaic, Yellow River Delta, China[J]. Bird Conservation International, 2013, 23(2): 184-198.

[16] 黄子强, 车纯广, 谭海涛, 等. 黄河三角洲水鸟多样性调查及种 群数量监测[J]. 山东林业科技, 2018, 48(2): 41-45. [Huang Z Q, Che C G, Tan H T, et al. Investigation on the diversity and population of waterbird in the Yellow River Delta Nature Reserve[J]. Shandong Forestry Science and Technology, 2018, 48(2): 41-45.]

[17] Grant S B, Saphores J D, Feldman D L, et al. Taking the "waste” out of "wastewater" for human water security and ecosystem sustainability[J]. Science, 2012, 337(6095): 681-686.

[18] 孙孝平, 张银龙, 曹铭昌, 等. 黄河三角洲自然保护区秋冬季 水鸟群落组成与生境关系分析 [J]. 生态与农村环境学报, 2015, 31(4): 514-521. [Sun X P, Zhang Y L, Cao M C, et al. Structure of waterfowl community in relation to habitat in the Yellow River Delta Nature Reserve in autumn migratory and wintering periods[J]. Journal of Ecology and Rural Environment, 2015, 31(4): 514-521.]

[19] 王立冬. 黄河三角洲水鸟种群动态变化[J]. 山东林业科技, 2012, (2): 67-70. [Wang L D. Waterfowl population change in Yellow River Delta[J]. Shandong Forestry Science and Technology, 2012,(2): 67-70.]

[20] 郝迎东. 黄河三角洲水鸟动态监测 [J]. 山东林业科技, 2012, 42 (4): 21-24. [Hao Y D. Dynamic monitoring of water birds in the Yellow River delta[J]. Shandong Forestry Science and Technology, 2012, 42(4): 21-24.]

[21] Cao M C, Xu H G, Le Z F, et al. A multi-scale approach to investigating the red-crowned crane-habitat relationship in the Yellow River Delta Nature Reserve, China: Implications for conservation [J]. Plos One, 2015, 10(6): e0129833.

[22] Tavares D C, Guadagnin D L, de Moura J F, et al. Environmental and anthropogenic factors structuring waterbird habitats of tropical coastal lagoons: Implications for management[J]. Biological Conservation, 2015, 186: 12-21.

[23] 刘月良. 黄河三角洲鸟类[M]. 北京: 中国林业出版社, 2013. [Liu Y L. Birds of the Yellow River Delta[M]. Beijing: China Forestry Publishing House, 2013.]

[24] King S, Elphick C S, Guadagnin D, et al. Effects of landscape features on waterbird use of rice fields[J]. Waterbirds, 2010, 33: 151159.

[25] Zhu C M, Zhang X, Huang Q H. Four decades of estuarine wetland changes in the Yellow River Delta based on Landsat observations between 1973 and 2013[J]. Water, 2018, DOI: 10.3390/ w10070933.

[26] 王薇. 黄河三角洲水土资源承载力综合评价研究[D]. 泰安: 山
东农业大学, 2012. [Wang W. Research on Comprehensive Evaluation of Water and Soil Resources Carrying Capacity in Yellow River Delta[D]. Tai' an: Shandong Agricultural University, 2012.]

[27] 李玉娟. 黄河三角洲高效生态经济区水资源保障能力分析-以 山东省东营市为例[J]. 河北农业科学, 2009, 13(8): 96-97. [Li Y J. Analysis on the support ability of water resource in high efficient ecological economic zone of Yellow River Delta: A case of Dongying, Shandong Province[J]. Hebei Agricultural Sciences, 2009, 13(8): 96-97.

[28] 董凯凯. 黄河三角洲退化湿地淡水恢复对土壤养分和植被的影 响研究[D]. 济南: 济南大学, 2011. [Dong K K. Effects of Freshwater Restoration on the Soil Nutrients and Vegetation in the Degraded Yellow River delta Wetlands[D]. Jinan: Jinan University, 2011.]

[29] 司敬玲, 张月明. 黄河三角洲入口河生态调水实践 $[J]$. 人民黄 河, 2013, 35(2): 30-32. [Si J L, Zhang Y M. Practice of ecological water dispatching in Diaokouhe waterway of the Yellow River Delta[J]. Yellow River, 2013, 35(2): 30-32.]

[30] 卓俊玲, 葛磊, 史雪廷. 黄河河口淡水湿地生态补水研究[J]. 水 生态学杂志, 2013, 34(2): 14-21. [Zhuo J L, Ge L, Shi X T. Study on eco- water supplement for freshwater wetlands in the Yellow River estuary[J]. Journal of Hydroecology, 2013, 34(2): 14-21.]

[31] 卜庆伟, 辛宏杰. 黄河三角洲非常规水资源综合利用[J]. 水资源 保护, 2012, 28(1): 42-45. [Pu Q W, Xin H J. Integrated utilization of unconventional water resources in Yellow River Delta[J]. Water Resources Protection, 2012, 28(1): 42-45.]

[32] Murray C G, Hamilton A J. Perspectives on wastewater treatmen wetlands and waterbird conservation[J]. Journal of Applied Ecology, 2010, 47(5): 976-985.

[33] Alves J A, Sutherland W J, Gill J A. Will improving wastewater treatment impact shorebirds? Effects of sewage discharges on estuarine invertebrates and birds[J]. Animal Conservation, 2012, 15 (1): 44-52

[34] Morris L, Petch D, May D, et al. Monitoring for a specific management objective: Protection of shorebird foraging habitat adjacent to a waste water treatment plant[J]. Environmental Monitoring and Assessment, 2017, DOI: 10.1007/s10661-017-5924-4.

[35] Gutierrez J S. Living in environments with contrasting salinities: A review of physiological and behavioural responses in waterbirds $[\mathrm{J}]$. Ardeola, 2014, 61(2): 233-256.

[36] 邹业爱. 崇明东滩水鸟群落对生境变化及湿地修复的响应[D]. 上海: 华东师范大学, 2014. [Zou Y A. Waterbird Community Response to Habitat Changes and Wetland Restoration Strategies in the Chongming Dongtan Wetlands, China[D]. Shanghai: East China Normal University, 2014.]

[37] 保尔森基金会. 中国滨海湿地保护管理战略研究项目 [R/OL] (2016- 09- 07) [2019- 12- 17]. https://max.book118.com/html/ 
2017/0907/132522793.shtm. [Paulson Institute. Blueprint of Coastal Wetland Conservation and Management in China[R/OL]. (2016- 09- 07) [2019- 12- 17]. https://max.book118.com/html/ 2017/0907/132522793.shtm.]
[38] 吕兄安, 程杰, 莫微, 等. 海水养殖污染与生态修复对策 [J]. 海洋 开发与管理, 2019, 36(11): 43-48. [Lv D A, Cheng J, Mo W, et al. Pollution and ecological restoration of mariculture[J]. Marine Development and Management, 2019, 36(11): 43-48.]

\title{
Comprehensive utilization of water resources in the Yellow River Delta for waterfowl habitat restoration
}

\author{
YUAN Xiu', SUN Yanyan², WANG Jiping ${ }^{3}$, YU Lili $^{2}$ \\ (1. Institutes of Science and Development, CAS, Beijing 100190, China; 2. Dongying Natural Resources Bureau, Dongying \\ 257091, China; 3. Research Center of Saline and Alkali Land of State Administration of Forestry and Grassland, Chinese \\ Academy of Forestry, Beijing 100091, China)
}

\begin{abstract}
The Yellow River Delta is an internationally important stopover place for waterfowl, but natural factors and human activities have resulted in loss of waterfowl habitat and biological diversity in this area. The habitat quality and diversity of waterfowl can be greatly improved by using fresh water to restore habitat. However, with fresh water shortage and large water consumption in agriculture, domestic use, and industry in this area, ecological water consumption is insufficient. In this case, how to utilize fresh water, sea water, and waste water adaptively considering the local conditions and give full play to the wetland function to protect biodiversity and purify the environment become the key problem to bird habitat restoration. This article summarized the diversity and the habitat requirements of waterfowl in the Yellow River Delta, and examined the water use status and the demands and challenges to the habitat of waterfowl in this area. We also analyzed the measures to restore waterfowl habitat, resource availability, restoration effects, challenges of waterfowl habitat restoration using fresh water, sea water, and waste water, and then proposed some research prospects. We hope that this article can provide a scientific foundation for the optimized measures of waterfowl habitat restoration for improving waterfowl diversity. Bases on the migration of waterfowl, temporal pattern of Yellow River water discharge, patch pattern of waterfowl habitat, status of water utilization, the wetland type after water diversion, and spatial distribution of different kinds of water resources, we recommend to comprehensively use fresh water, sea water, and waste water to restore waterfowl habitat by considering the temporal patterns of water supply, spatial arrangements of habitats, and a combination of the different habitat types at the same patch, with the purpose of giving full play to the wetland function and improving the biological diversity.
\end{abstract}

Key words: waterfowl; habitat; freshwater; waste water; sea water; coastal wetland; biodiversity; Yellow River Delta 